\title{
Endoscopic submucosal dissection of gastric ectopic pancreas
}

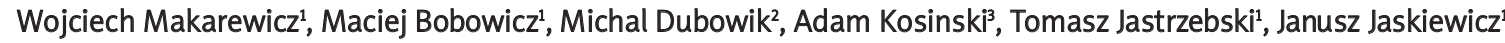 \\ 1Department of Oncological Surgery, University Clinical Center, Medical University of Gdansk, Poland \\ 2Department of Gastroenterology and Hepatology, University Clinical Center, Medical University of Gdansk, Poland \\ ${ }^{3}$ Department of Clinical Anatomy, Medical University of Gdansk, Poland
}

Videosurgery Miniinv 2013; 8 (3): 249-252 DOI: $10.5114 /$ wiitm.2011.33709

\begin{abstract}
Patients with gastric tumors usually present with symptoms of discomfort or pain in the epigastrium, regurgitations, nausea, vomiting or melena. Treatment options include open and laparoscopic total or partial gastrectomy and recently endoscopic mucosal resection. A case of successful endoscopic submucosal dissection is described with the unusual pathological finding of heterotopic pancreatic tissue forming a gastric tumor. The 67-year-old male patient was operated on due to the initial diagnosis of gastro-intestinal stromal tumor of the gastric trunk. Two intra-operative biopsies were negative for cancer cells. Submucosal endoscopic dissection was performed with IT and Hook knives (Olympus). A literature review was performed. The operative time was $180 \mathrm{~min}$ with hospital stay of 6 days. During the injection of the carmine dye and the air insufflation pneumoperitoneum occurred and remained clinically silent during the observation period. The pathology result showed a heterotopic pancreatic tissue type 2 according to Heinrich's classification with microfoci of intestinal metaplasia. Preoperative diagnostics of gastric masses might be misleading and such tumors not necessarily should be excised. There are several surgical options with endoscopic submucosal dissection being probably the safest one and a non-disabling approach. Patients tolerate that kind of surgery well with good postoperative functional outcomes.
\end{abstract}

Key words: endoscopic submucosal dissection, heterotopic pancreas, ectopic pancreas, stomach.

\section{Introduction}

Patients with gastric tumors usually present with symptoms of discomfort or pain in the epigastrium, regurgitations, nausea, vomiting or melena [1]. Most of these symptoms are not specific and thus require additional examinations, e.g. gastroscopy with biopsy and urease test, computed tomography scans, and preferably endoscopic ultrasound scan as well [2, 3]. Most gastric tumors turn out to be neoplasms and require a complete resection by means of total gastrectomy with adequate nodal dissection [2]. There is a limited space reserved for partial gastric resections especially sleeve gastrectomy for gastrointestinal stromal tumors (GIST) located on the greater curvature $[2,4]$. Progress of the equipment and the operative techniques allows such operations to be performed also in laparoscopic fashion [5-7]. In recent years some reports have started to emerge on submucosal dissections for benign gastric tumors as well [8-10].

In this article the authors present a difficult patient, who had multiple available attempts to assess the gastric tumor that failed leaving no diagnosis and a large tumor for the surgical oncology team with the decision on the operation extent and thus further patient quality of life and disease-free 
survival. The diagnostic and treatment pathway with crucial turns is described. Successful endoscopic submucosal dissection was performed with the unusual pathology finding of heterotopic pancreatic tissue forming gastric tumor.

\section{Case report}

A 67-year-old male patient was referred due to the initial diagnosis of gastro-intestinal stromal tumor of the gastric trunk. Gastroscopy was performed and showed a $3 \mathrm{~cm}$ in diameter submucosal gastric tumor located in the lower part of the anterior wall of the gastric trunk. Endoscopic biopsy was done. The pathology results were inconclusive as samples did not contain dipper layers of the submucosa and showed only moderate chronic inflammatory changes. Subsequent computed tomography scan (CT) visualized a $15 \mathrm{~mm}$ thickening of the gastric wall spreading at the area of $35 \mathrm{~mm}$, containing some microcalcifications. The scan did not show lymphadenopathy or any local or distal spread of the disease. The patient has been previously diagnosed with stable ischemic heart disease, arterial hypertension, chronic obstructive pulmonary disease, chronic renal insufficiency and benign prostate hyperplasia. On admission the patient was on polypharmacy due to multiple conditions. Previous surgical history consisted of right inguinal hernia repair only.

\section{Operation}

The patient was operated on in the supine position under general anesthesia. During the operation the biopsy and the intra-operative pathology examination were done twice. Both were negative for can-

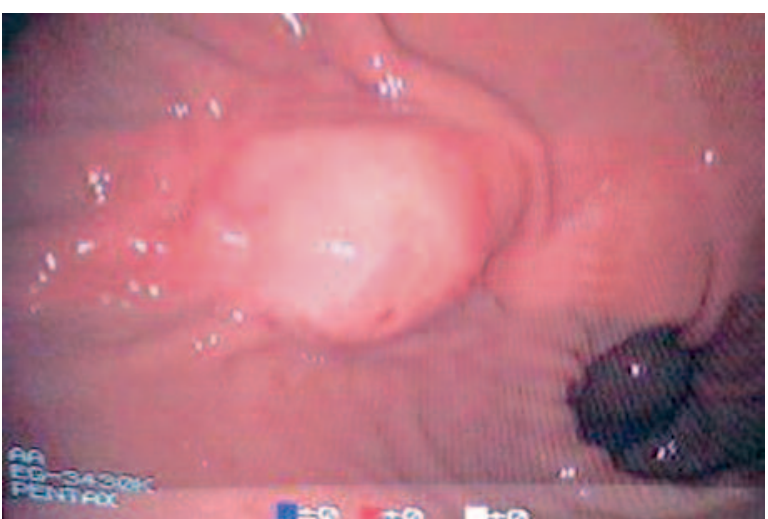

Photo 1. Gastroscopy view of the gastric heterotopic pancreas cer cells. Then the tumor's circumference was marked using the Flex knife (KD-630L, Olympus, Japan). It was followed by the injection of $0.9 \%$ Normal Saline with Adrenalin and Indigo Carmin 0.2\% (J2F; Issy les Moulineaux; France). Submucosal dissection was performed with an insulation-tip diathermic knife (IT knife KD-610L, Olympus, Japan) and Hook knife (KD-620LR, Olympus, Japan).

The initial report of the pathology examination directly following the operation stated that the resected gastric wall tissue was a heterotopic pancreatic tissue and therefore it did not force pre-operatively planned gastric sleeve resection (Photos 1 and 2).

\section{Results}

The operative time was $180 \mathrm{~min}$. The intra-operative blood loss was insignificant. During the injection of carmine dye and the air insufflation a puncture in the stomach serosa was made and some of the air passed into the peritoneal cavity. The diagnosis was based on the postoperative abdominal X-ray examination only and the ultrasound scan excluded the presence of free fluid in the abdomen. The inflammatory response expressed by the white cell count was in the normal range and the C-reactive protein was slightly increased. The pneumoperitoneum remained clinically silent during the observation period. Observation of the abdomen prolonged the hospital stay up to 6 days. The postoperative period was not complicated. The pathology result showed a heterotopic pancreatic tissue with microfoci of intestinal metaplasia (gastropathy corporalis) and non-specific chronic inflammatory changes that can be categorized as heterotopic pancreas type 2 according to

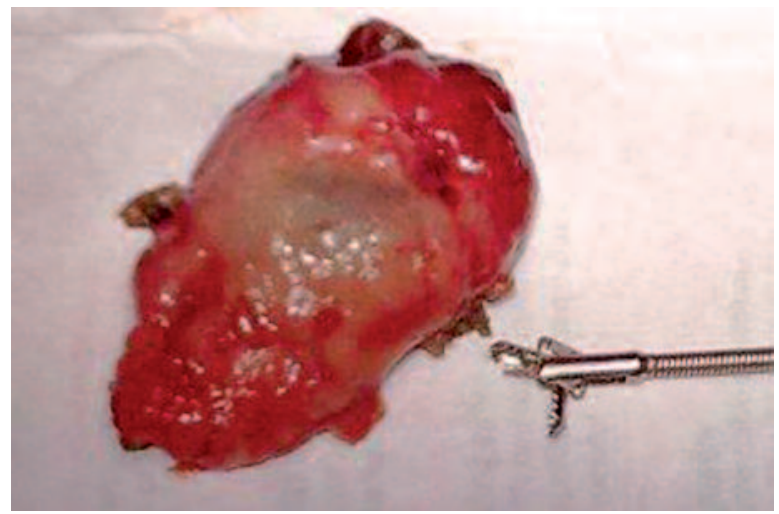

Photo 2. Excised specimen 
Heinrich's classification. A follow-up visit and control gastroscopy were performed 6 weeks after surgery, showing only some scarring in the area of the excised heterotopic pancreas (Photo 3).

\section{Discussion}

The first report on heterotopic pancreas by Schultz was published in 1729 [11]. It occurs with 0.5-13\% frequency in the general population [12] as a result of fetal migration of pancreatic tissue during gastrointestinal tract formation with further development in the ectopic area [13]. Ectopic pancreas has the same genetic expression with normal exocrine and endocrine function [11]. The three main locations of ectopic pancreas are the stomach, duodenum and jejunum, with some other less frequent occurrences [14]. In the present case, the ectopic pancreas was located in the submucosa of the stomach's corpus. This is consistent with observations of other authors with three fourths of pancreatic tissue in the stomach spreading only in the submucosa [12]. The differential diagnosis includes GIST, gastrointestinal autonomic nerve tumors (GANT), lymphoma and multiple other malignancies $[11,15]$.

Most of the ectopic pancreas cases, especially small ones, remain asymptomatic during the lifespan. The first symptoms, usually pain, occur around the fifth decade of life and in some cases they manifest as emergencies such as gastrointestinal bleeding, gastric outlet obstruction or perforation [16-19]. The described patient presented initially with pain that did not respond to standard analgesics and required additional endoscopy and radiology evaluation to elicit the diagnosis.

The endoscopic picture of the heterotopic pancreas in the stomachs wall has been described as an elevated delomorphic submucosal tumor that has a normal mucosa over it with characteristic central umbilication [20]. In some patients the endoscopic picture is not that specific, e.g. there is a lack of the central umbilication like in the present case and the tumor might be misinterpreted for GIST or another malignancy. In the case of ectopic pancreas other imaging modalities such as ultrasound scan and computed tomography seem not very helpful in the diagnosis [13]. At present the best option for the assessment and differentiation of gastric wall tumors is the transoral endoscopic ultrasound scan. One problem in several countries with a public health sys-

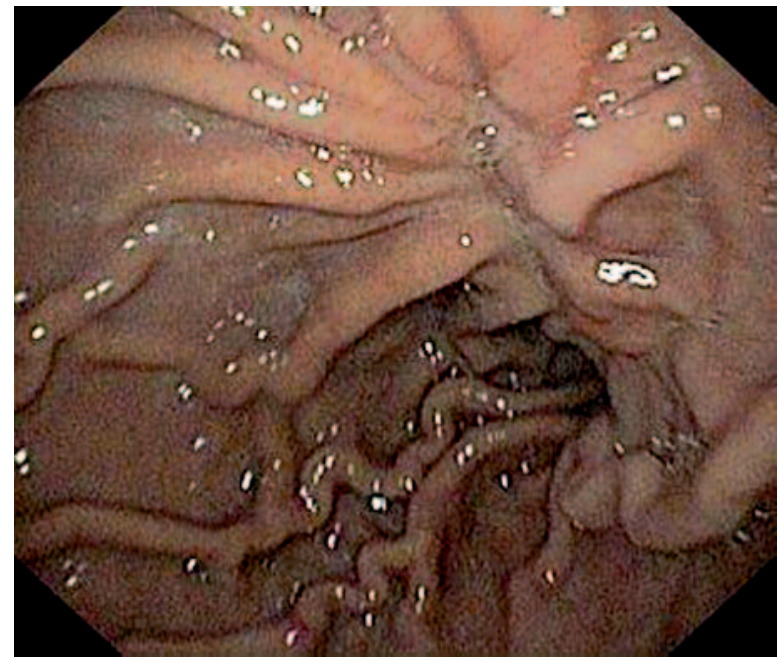

Photo 3. View from control gastroscopy with visible scarring of gastric mucosa

tem is availability of the test. In the authors' province this examination was not available at the time, therefore it was not carried out.

Interestingly, most authors report normal results of the biopsies taken during the diagnostic gastroscopy [19]. The pathology result of the pre-operative gastric biopsy showed normal gastric mucosa in the described patient. Intra-operative incisional biopsy gave the same result and just the final report of the excised tumor gave the result of an ectopic pancreas. All these difficulties with proper identification of ectopic pancreas might lead in some patients to unnecessary partial or total gastrectomies in less experienced centers.

In the case of ectopic pancreas there is an ongoing academic debate as to whether it should be excised. Protagonists say that due to the fact that it is a normal pancreatic tissue it is predisposed to all typical pancreatic disorders from acute and chronic pancreatitis to neoplastic transformation, and therefore it should be removed as early as possible as the means of prophylaxis [20, 21]. Antagonists advocate conservative management with surgical intervention reserved only for patients with severe pain, actual disordered function or emergency presentations [13].

There are three modes of surgical intervention at present: first, classic laparotomy with wedge resection; second, laparoscopic sleeve resection; and third, endoscopic submucosal dissection (ESD) [8-10, 22, 23]. The last approach has been gaining popularity over the last decade. In the present case initially laparoscopic wedge resection was planned with 
endoscopic assistance to visualize the tumor. During gastroscopy the multidisciplinary team decided to perform ESD with intra-operative pathology examination. The operative time of $3 \mathrm{~h}$ was much longer than the anticipated duration of the laparoscopic procedure; nevertheless in the team's opinion smaller extent of the operation and no need for full-thickness gastric wall resection were much more beneficial for the patient. The only perioperative complication was abdominal pneumoperitoneum that occurred during the injection of the carmine dye and the air insufflation. Pneumoperitoneum was not associated with clinical signs of perforation, and on serial control abdominal X-ray has shown steady improvement.

In conclusion, some gastric masses mimicking neoplasms are virtually benign structures, albeit in an inappropriate location such as the gastric heterotopic pancreas. Preoperative diagnostics might be misleading and such tumors not necessarily ought to be excised. There are several surgical options with endoscopic submucosal dissection being probably the safest one and a non-debilitating approach. Patients tolerate that kind of surgery well, with good postoperative functional outcomes.

\section{Acknowledgments}

The authors acknowledge Joanna Jassem-Bobowicz MD from the Medical University of Gdansk, Poland, for her invaluable involvement in the manuscript preparation.

\section{References}

1. Layke JC, Lopez PP. Gastric cancer: diagnosis and treatment options. Am Fam Physician 2004; 69: 1133-41.

2. Okines A, Verheij M, Allum W, et al.; ESMO Guidelines Working Group. Gastric cancer: ESMO Clinical Practice Guidelines for diagnosis, treatment and follow-up. Ann Oncol 2010; 21 (Suppl. 5): v50-4.

3. Wierzchowski P, Dąbrowiecki S, Szczęsny W. Urgent endoscopy in elderly patients with non-variceal upper gastrointestinal bleeding. Videosurgery Miniinv 2012; 7: 246-50.

4. Sákra L, Šiller J, Vyhnálek P, Hácová M. Surgical treatment of gastric and small bowel gastrointestinal stromal tumours. Videosurgery Miniinv 2011; 6: 138-43.

5. Privette A, McCahill L, Borrazzo E, et al. Laparoscopic approaches to resection of suspected gastric gastrointestinal stromal tumors based on tumor location. Surg Endosc 2008; 22: 487-94.

6. Melstrom LG, Phillips JD, Bentrem DJ, Wayne JD. Laparoscopic versus open resection of gastric gastrointestinal stromal tumors. Am J Clin Oncol 2012; 35: 451
7. Yoshimura F, Inaba K, Kawamura Y, et al. Clinical outcome and clinicopathological characteristics of recurrence after laparoscopic gastrectomy for advanced gastric cancer. Digestion 2011; 83: 184-90.

8. Khashab MA, Cummings OW, DeWitt JM. Ligation-assisted endoscopic mucosal resection of gastric heterotopic pancreas. World J Gastroenterol 2009; 15: 2805-8.

9. Kojima T, Takahashi H, Parra-Blanco A, et al. Diagnosis of submucosal tumor of the upper GI tract by endoscopic resection. Gastrointest Endosc 1999; 50: 516-22.

10. Faigel DO, Gopal D, Weeks DA, Corless C. Cap-assisted endoscopic submucosal resection of a pancreatic rest. Gastrointest Endosc 2001; 54: 782-4.

11. Christodoulidis G, Zacharoulis D, Barbanis S, et al. Heterotopic pancreas in the stomach: a case report and literature review. World I Gastroenterol 2007; 13: 6098-100.

12. DeBord JR, Majarakis JD, Nyhus LM. An unusual case of heterotopic pancreas of the stomach. Am J Surg 1981; 141: 269-73.

13. Sadeghi NR, Godambe A, Shienbaum AJ, Alloy A. Premalignant gastric heterotopic pancreas. Gastroenterol Hepatol 2008; 4: 218-21.

14. Kilman WJ, Berk RN. The spectrum of radiographic features of aberrant pancreatic rests involving the stomach. Radiology 1977; 123: 291-6.

15. Yuan Z, Chen J, Zheng Q, et al. Heterotopic pancreas in the gastrointestinal tract. World J Gastroenterol 2009; 15: 3701-3.

16. Ormarsson OT, Gudmundsdottir I, Marvik R. Diagnosis and treatment of gastric heterotopic pancreas. World I Surg 2006; 30 : $1682-9$.

17. Teke Z, Kabay B, Kelten C, et al. Ectopic pancreas of the gastric antrum contiguous to a gastrointestinal stromal tumor manifesting as upper gastrointestinal bleeding: report of a case. Surg Today 2007; 37: 74-7.

18. Huang YC, Chen HM, Jan YY, et al. Ectopic pancreas with gastric outlet obstruction: report of two cases and literature review. Chang Gung Med I 2002; 25: 485-90.

19. Gurocak B, Gokturk HS, Kayacetin S, Bakdik S. A rare case of heterotopic pancreas in the stomach which caused closed perforation. Neth J Med 2009; 67: 285-7.

20. Agale SV, Agale VG, Zode RR, et al. Heterotopic pancreas involving stomach and duodenum. J Assoc Physicians India 2009; 57 : 653-7.

21. Jiang LX, Xu J, Wang XW, et al. Gastric outlet obstruction caused by heterotopic pancreas: a case report and a quick review. World J Gastroenterol 2008; 14: 6757-9.

22. Priego P, Rivadulla I, Daroca J, et al. Laparoscopic resection of heterotopic pancreatic tissue in the gastric antrum. Rev Esp Enferm Dig 2009; 101: 732-3.

23. Margolin DJ. Endoscopy-assisted laparoscopic resection of gastric heterotopic pancreas. Am Surg 2008; 74: 829-31.

Received: 26.11.2012, accepted: 2.02.2013. 